\title{
Acanthocollaritrema umbilicatum Travassos, Freitas \& Bührnheim, 1965 (Digenea: Acanthocollaritrematidae) from the Common Snook, Centropomus undecimalis, from Itamaracá, State of Pernambuco, Brazil
}

\author{
Ricardo Berteaux Robaldo/ ${ }^{+}$, Isaíras Pereira Padovan* \\ Departamento de Oceanografia * Departamento de Histologia e Embriologia, Universidade Federal de \\ Pernambuco, Av. Moraes Rego 1235, Cidade Universitária, 50760-420 Recife, PE, Brasil
}

\begin{abstract}
Acanthocollaritrema umbilicatum Travassos, Freitas and Bührnheim, 1965, is the only species of Acanthocollaritrematidae described up to the moment. The systematic position of this species and the validity of the family has been questioned by the possible presence of a gonotyl and a genital atrium associated to the acetabulum. In this paper, specimens of this trematode, collected from Centropomus undecimalis cultivated at Itamaracá, State of Pernambuco, northeast Brazil, were studied under optical and scanning electron microscopy, and compared with available sintypes. Gonotyl and genital atrium were not observed and both family and species are considered valid taxonomic entities. A. umbilicatum is redescribed with the adition of new morphological information.
\end{abstract}

Key words: Acanthocollaritrema umbilicatum - digenea - Centropomus undecimalis - Brazil

Acanthocollaritrema umbilicatum Travassos, Freitas \& Bührnheim, 1965, is the only species described in Acanthocollaritrematidae up to the moment. This species has been reported only from Centropomus undecimalis collected along the coast of the states of Espírito Santo and Rio de Janeiro, Brazil (Travassos et al. 1965, Gomes et al. 1972, Wallet \& Kohn 1987). Its systematic position was questioned by Gomes et al. (1972), who reported a gonotyl associated to the acetabulum.

During studies on the helminthofauna of cultured fishes in the northeast of Brazil this trematode was found infecting the digestive tract of $C$. undecimalis. New characteristics observed in these specimens, mostly using scanning electron microscopy (SEM), answered the above-mentioned question and provided additional information presented in the redescription of this species.

\section{MATERIALS AND METHODS}

The 107 fishes examined were obtained from ponds in the Fish Culture Station, "Universidade Federal de Pernambuco", Itamaracá Island, Pernambuco, Brazil. For studies with optical microscopy, the helminths were fixed (while still alive) under pressure with AFA solution ( $2 \%$ ace-

\footnotetext{
${ }^{+}$Corresponding author. Fax: +55-53-232.9716. E-mail: dqmrbr@super.furg.br Received 16 May 1997 Acepted 18 February 1998
}

tic acid, $3 \%$ formaldehyde and $95 \%$ of $70 \%$ ethanol) during a period of $24 \mathrm{hr}$, preserved in $70 \%$ ethanol and stained in Semichon's carmine. The helminths were, then, dehydrated in graded ethanol, cleared with beechwood creosote, and mounted in permanent slides using Canada balsam. Specimens for SEM were placed in $2.5 \%$ glutaraldehyde, buffered with cacodilate, at $4^{\circ} \mathrm{C}$ during $3-4 \mathrm{hr}$, washed with a solution of the same buffer and postfixed for $2 \mathrm{hr}$ with $1 \%$ osmium tetroxide buffered with cacodilate at room temperature. The worms were then, dehydrated with increasing concentrations of ethanol, dryed with $\mathrm{CO}_{2}$ and ethanol (Critical Point Dryer, HITACHI), and coated with gold (Fine Coat, JEOL). The observations and photographs were made with a JEOL T-200 scanning electron microscope.

Measurements are given in micrometers, unless otherwise indicated, with mean followed by minimum and maximum values in parenthesis.

The material studied is deposited in the Helminthological Collection of the Oswaldo Cruz Institute (accession No.: 33.711-33.715).

\section{RESULTS}

Acanthocollaritrematidae Travassos, Freitas et Bührnheim, 1965

Acanthocollaritrema umbilicatum Travassos, Freitas et Bührnheim, 1965

Host: Centropomus undecimalis (Bloch, 1792). Sites: anterior intestine and, predominantly, pyloric ceca. 
Redescription: based on 10 mature specimens. Body, elongate, contour elliptic $1.572 \mathrm{~mm}(0.77$ $3.00)$ long by $0.497 \mathrm{~mm}(0.300-0.884)$ wide (Figs $1,5)$. Tegument densely covered with imbricated spines; spines scale-like with serrated edges, corrugated surface; spines absent in ventral region in front and around acetabulum (Figs 6,8) uniformly distributed on rest of tegument forming an outer layer of 5 (4-9) thick. Anterior end of body protractile with two rows of circumoral spines; first row, on the oral sucker, with 68 (65-80) simple, large cuneiform (in lateral view) spines, which can be protracted or retracted in grooves of tegument; large spines 12 (8-15) long, 4 (3-4) wide; second row immediately anterior to first, forming a constriction zone between oral sucker and anterior region of body, formed by densely grouped elongate spines, with sharp serrated edges, smaller than those from the first row (Figs 2, 7). Posterior end of body round. Portion of body anterior to the vitellaria rich in dermal glandular cells (Fig. 2). Oral sucker terminal, 75 (52-107) long, 111 (73166) wide. Acetabulum postequatorial, postesticular, median, protractile, usually embedded in parenchyma (when retried), 88 (57-117) long, 86 (62112) wide (Fig. 8). Sucker length ratio 1:1.28 (1:0.8 - 1:1.84). Prepharynx 60 (18-122) long, 18 (1323) wide. Muscular pharynx 60 (52-70) long, 50 (31-67) wide. Esophagus short. Intestinal ceca terminating near posterior extremity, convergent in intertesticular fields. Cecal bifurcation approximately half distance between pharynx and anterior border of vitellaria. Genital pore inconspicuous, mid dextral, anterior to acetabulum. Seminal vesicle bipartite, median, post-testicular, preacetabular; anterior portion of seminal vesicle 96 (75-130) long, 57 (39-86) wide; posterior portion 113 (60-192) long by 71 (47-117) wide, terminating in short, muscular ejaculatory duct (Fig. 3). Seminal receptacle postero-dorsal to seminal vesicle. Cirrus pouch absent. Testes subsymetrical, equatorial, with smooth contour, right testis 188 (94-370) long, 135 (81-225) wide; left testis 230 (104-360) long, 167 (117-260) wide. Germarium strongly lobed, laterally expanded, at posterior third of body, anterior portion partially overlapping acetabular field; lobes of germarium distributed in intercecal, cecal, extracecal fields; germarium occupies space of approximately 170 (70-330) long, 389 (226-580) wide. Mehlis' gland, Laurer's canal not observed. Vitellaria formed by large follicles, irregularly disposed dorso-transversely, from region posterior to cecal bifurcation to pretesticular level; vitelline ducts inconspicuous, lateral to seminal vesicle, fusing near posterior region of this vesicle. Uterus formed by numerous coils distributed from posterior limit of vitellaria to posterior extremity, filling most of the hindbody. Metraterm joins ejaculatory duct forming a hermafrodict duct (Fig. 3). Eggs yellow to light brown, operculated; uncollapsed eggs 17 (15-18) long, 10 (10-12) wide. Excretory vesicle extensive, bifurcation immediately post-acetabular, arms extending to bifurcation of intestinal cecae, when full, occupying approximately all intercecal area; pretesticular portion of excretory vesicle with the arms enlarged with wrinkled walls (observed in vivo, Fig. 4). Excretory pore subterminal, ventral. Surface of preacetabular ventral region, lacking spines; tegument with three transverse grooves, groups of papiliform structures, similar to tubercules, apparently with secretory function; first group approximately equatorial with 10 (5-14) papillae; second, near to anterior border of acetabulum, with 19 (1722) papillae; third immediately preacetabular with 7 (6-9) papillae (Figs 8-10).

\section{DISCUSSION}

In the diagnosis of Acanthocollaritrematidae presented by Yamaguti (1971), he added details about the presence of seminal receptacle, ejaculatory and hermafrodict ducts, and reported that the acetabulum of species of Acanthocollaritrematidae is embedded in the parenchyma and opens into a genital atrium. According to Gomes et al. (1972), the use of a different stain (cotton blue) allows observation of a genital atrium complex in the acetabular region. They also state that this complex, with a sac-like form, had an opening formed by a muscular ring, similar to a third sucker, characterizing a gonotyl. Based on this character they suggested that Acanthocollaritrematinae must be supported but should be allocated in Cryptogonimidae (Ward, 1917) Cirurea, 1933, considering Acanthocollaritrematidae not valid. Wallet and Kohn (1987), did not mention this proposal and placed the species in Acanthocollaritrematidae.

The material analyzed in this study by optical and electronic microscopy seems to agree and to be more close to the description of Yamaguti (1971). However, studying living specimens, it is possible to observe that the depression formed at the acetabulum-genital region, named "genital atrium" by Yamaguti (1971), is not a permanent structure, being formed only when the acetabulum is retracted. Examining both live and fixed specimens, when the acetabulum is everted, gonotyl and genital atrium are not visible (Fig. 3).

None of the reports on A. umbilicatum mentioned the etymology of the adopted specific epithet. Apparently, "umbilicatum" (having a form of navel, in Latin) is related to the median ventral postequatorial position and the small size of the acetabulum. 

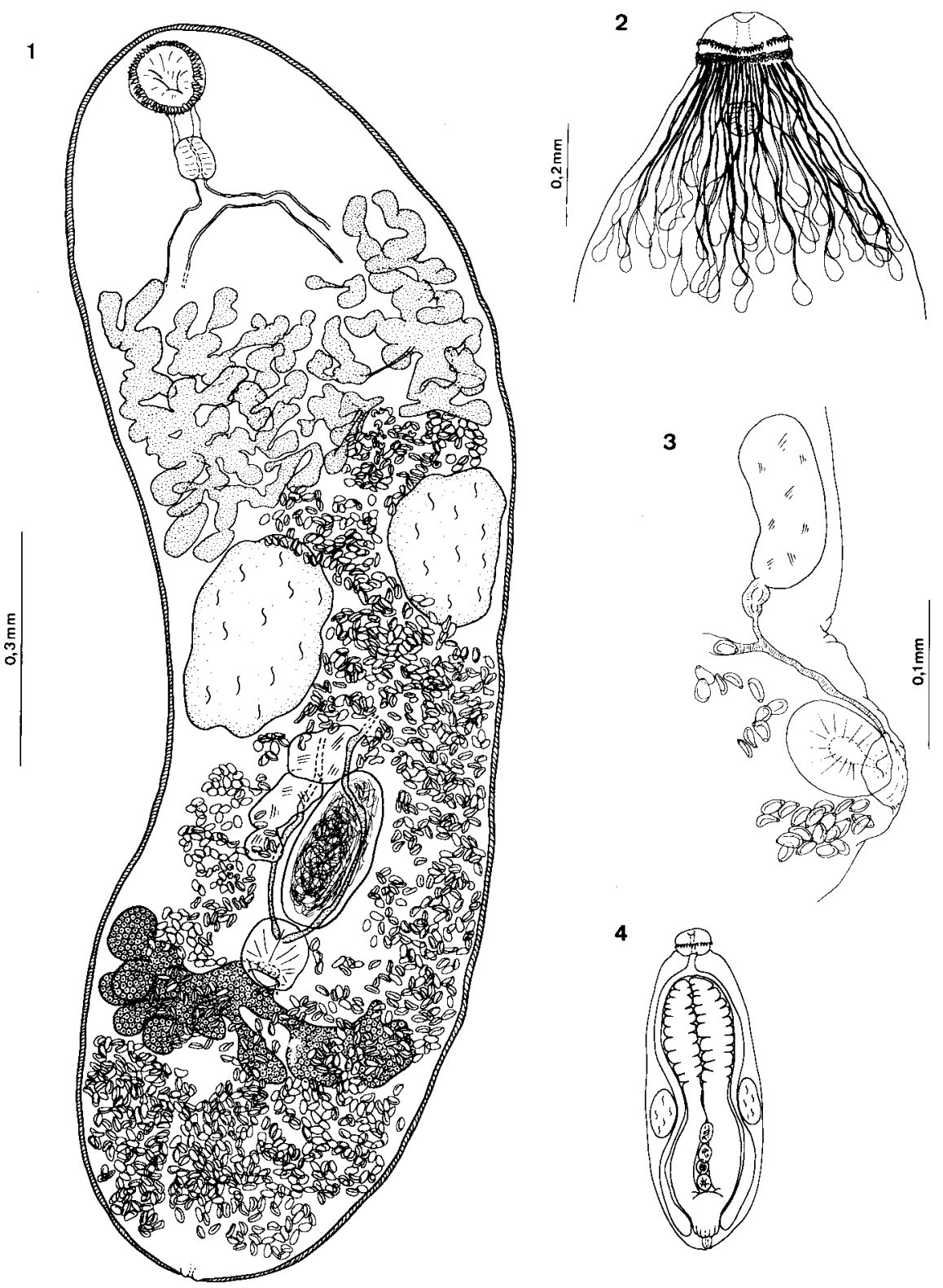

4

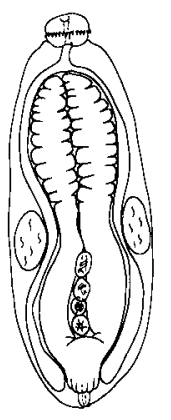

Acanthocollaritrema umbilicatum. Fig. 1: adult, ventral view. Fig. 2: ventral view of anterior end rich in celular glands in parenchyma. Fig. 3: lateral view of ventro acetabular region showing details of ejaculatory duct, hermafroditic duct, acetabulum everted and eggs. Fig. 4: schematic drawing of juvenile specimen, showing details of excretory vesicle ("live", ventral view).

The specimens collected in this study differ from those described by Travassos et al. (1965) because of the presence of papiliform projections on the ventral region, the number of spines on the oral sucker, and the small size of eggs. When the sintypes $29.943 \mathrm{a}, \mathrm{b}, \mathrm{c}, \mathrm{d}, \mathrm{e}, \mathrm{f}, \mathrm{g}$ and h (deposited by the authors of species) were examined by optical microscopy with phase contrast, it became evident that the number of spines on the oral sucker ranged from 43 to 52 , distinct from the number (36) reported in the original description. These numbers may be even higher since it was not possible to count all the spines of the oral sucker in any sintype examined. During the analysis of the collected material, we also observed a variation on the number of these spines. Immature specimens with conspicuous eyespot depict 53 to 57 spines on oral sucker; longer immature specimens with- 


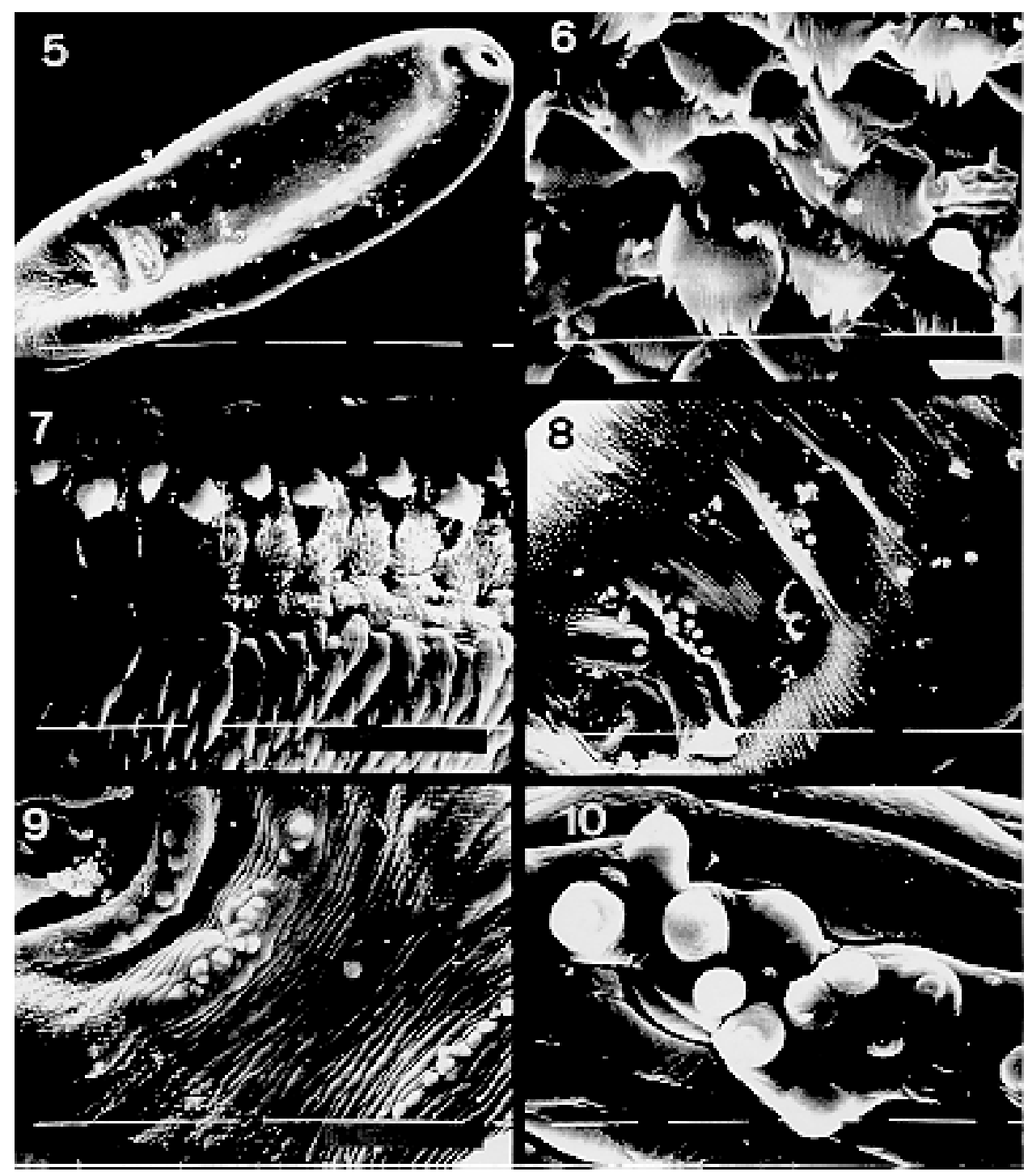

Scaning electronmicrographies of Acanthocollaritrema umbilicatum. Fig. 5: adult, ventral view. Bar =0.1mm. Fig. 6: scale-like serrated spines of tegument. Bar $=0.01 \mathrm{~mm}$. Fig. 7 : detail of first and second spine rows at the oral sucker level. Bar $=0.01 \mathrm{~mm}$. Fig. 8: embedded acetabulum and ventral region unspined. $\mathrm{Bar}=0.1 \mathrm{~mm}$. Fig. 9: three ventral tegumental pads with papiliform projectons Bar $=0.1 \mathrm{~mm}$. Fig. 10: detail of papiliform projections of ventral pads. $\mathrm{Bar}=0.01 \mathrm{~mm}$.

out eyespot or with just dispersed granules showed from 62 to 65 spines. Such differences suggest possible ontogenetic variation.

The fact that the papiliform projections were not reported by previous authors, may be associated to the difficulty in observing these structures with optical microscope. In the material studied herein, the presence of these features could not be clearly defined using a stereomicroscope with incident light and their existence were only confirmed with the SEM. Additionaly, these structures could not be observed in the specimens deposited by
Travassos et al. (1965) and Gomes et al. (1972) under optical microscope.

Based solely on egg size differences, it is not possible to make a distinction between the material studied herein and the original description of the species. Similar observations were made by Gomes et al. (1972) and Wallet and Kohn (1987).

Therefore, we conclude that the studied specimens are A. umbilicatum, and that Acanthocollaritrematidae Travassos, Freitas and Bührnheim, 1965 is valid, but the new features described herein must be added to the description of this species. 


\section{ACKNOWLEDGEMENTS}

To the technical staff of Laboratório de Imunopatologia Keizo Azami for their technical assistance with scanning electron microscopy. To the Departamento de Oceanografia, Universidade Federal de Pernambuco for providing the fish examined. To Dr André Schmitt and Dr Joaber Pereira Junior who revised the manuscript and Dr Dely Noronha, chairman of helminthological collection of Instituto Oswaldo Cruz, who has kindly made available all the sintypes used in this work.

\section{REFERENCES}

Gomes DC, Fabio SP, Rolas FJT 1972. Contribuição para o conhecimento dos parasitos de peixes do litoral da Guanabara - Parte I. Mem Inst Oswaldo Cruz 70: 541-553.

Travassos L, Freitas JFT, Bührnheim PF 1965. Trematódeos de peixes do litoral Capixaba: Acanthocollaritrema umbilicatum gen. n., sp. n. (Acanthocollaritrematidae fam. n.), parasito de robalo. Atas Soc Biol Rio de Janeiro 9: 49-51.

Wallet M, Kohn A 1987. Trematodes parasites de poisson marins du littoral de Rio de Janeiro, Brésil. Mem Inst Oswaldo Cruz 82: 21-27.

Yamaguti S 1971. Sinopsis of Digenetic Trematodes of Vertebrates, Vol. 1, 1,074 pp., Vol. 2, 349 plates, Keigaku Publ. Co., Tokyo. 
